\title{
Ocean planning in a changing climate
}

To the Editor - The ways in which humans use ocean resources needs to be carefully planned over space and time, in order to minimize conflicts and foster compatibilities among uses, and between uses and the environment ${ }^{1}$. This planning process, most often termed marine spatial planning, has been developed worldwide from coastal to open-ocean regions as a way to foster sustainable ocean management and governance. Marine spatial planning is currently being developed in about 50 countries, yet despite its widespread acceptance and uptake, it still faces many political, social, economic and environmental challenges. Here we suggest that global climate change will present an additional, evolving challenge that requires flexible and adaptive ocean planning.

Ocean warming, ocean acidification and sea-level rise are all expected to significantly alter present ocean conditions ${ }^{2}$, as are additional drivers of change (Fig. 1). As a consequence, marine ecosystem services will be redistributed ${ }^{2}$, and ocean uses that rely on those services will undergo spatial and temporal change through local decrease or increase, or relocation.

Some ocean uses, such as fisheries or conservation ${ }^{3,4}$, are likely to be more vulnerable, that is, more exposed and less resilient to climate change effects. Others, such as shipping ${ }^{5}$ are likely to be less affected globally (Fig. 1). As ocean uses have different social and economic importance for different nations and regions, the influence of these global vulnerabilities on ocean planning will vary from place to place. For example, a specific use of the oceans may be only moderately vulnerable to a changing climate but yet extremely valuable for a region's socio-economy. If so, it will be highly significant for local ocean planning processes. The spatial context is thus of paramount relevance to assess the extent of impacts.

The best way for ocean planning efforts to respond to potential future alterations is to become increasingly flexible and adaptive today ${ }^{6,7}$. Regional and national policies for ocean planning, as well as individual processes (both in terms of legislation and of actual ocean plans) need to be able to effectively incorporate change to thrive in a dynamic and uncertain future. Operational approaches to foster such flexibility, such as just-in-time planning, dynamic ocean management or dynamic ocean
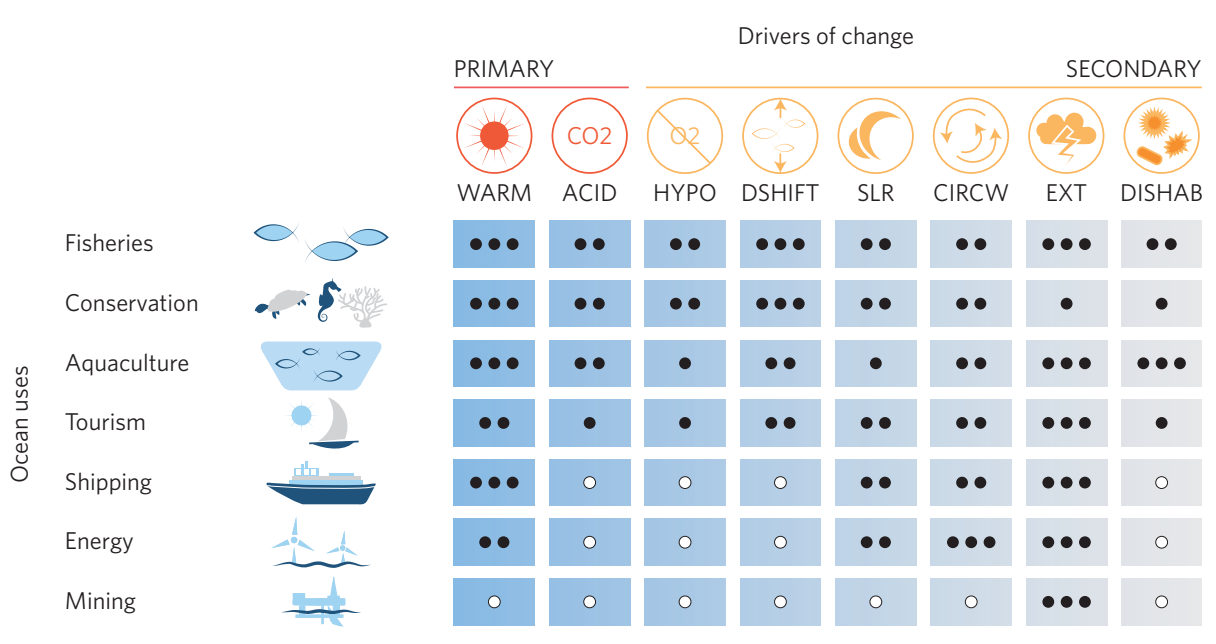

Direct impact degree: high $(\bullet \bullet \bullet)$, medium $(\bullet \bullet)$, low $(\bullet)$, none (O)

Figure 1 | Vulnerability of ocean uses to climate change. We present the direct impact estimate of climate-related drivers of change on different ocean uses. Primary drivers of change directly stem from greenhouse gas effects, whereas secondary drivers of change result from other drivers (primary and/or secondary). WARM, warming; ACID, acidification; HYPO, hypoxia; DSHIFT, distributional shifts; SLR, sea-level rise; CIRCW, circulation and winds; EXT, extreme events; DISHAB, diseases and harmful algae blooms. For the derivation of the estimated impacts, see Supplementary Information.

zoning $^{8-10}$ must be explicitly identified, and implemented. Subsequently, regular revision mechanisms ${ }^{7}$ must be established.

There is an underlying premise for all of this to be possible: climate change must be recognized as a challenge in both policies and processes of ocean planning. Only then can the climate dimension be properly encompassed, and a long-term, sustainable vision for the use of the ocean be ensured. $\square$

References

1. Ehler, C. \& Douvere, F. Marine Spatial Planning: A Step-By-Step Approach Toward Ecosystem-Based Management (UNESCO, 2009).

2. IPCC Climate Change 2013: The Physical Science Basis (eds Stocker, T. F. et al.) (Cambridge Univ. Press, 2013).

3. Barange, M. et al. Nat. Clim. Change 4, 211-216 (2014).

4. Magris, R. A., Pressey, R. L., Weeks, R. \& Ban, N. C. Biol. Conserv. 170, 207-221 (2014)

5. Smith, L. C. \& Stephenson, S. R. Proc. Natl Acad. Sci. USA 110, E1191-E1195 (2013).

6. Chapin, F. S. et al. Trends Ecol. Evol. 25, 241-249 (2010).

7. Allen, C. R., Fontaine, J. J., Pope, K. L. \& Garmestani, A. S Adaptive management for a turbulent future. J. Environ. Manage. 92, 1339-1345 (2011).

8. Maxwell, S. M. et al. Marine Policy 58, 42-50 (2015).

9. Alfasi, N. \& Portugali, J. Cities 21, 29-39 (2004).

10. Agardy, T. S. Ocean Zoning: Making Marine Management More Effective (Earthscan, 2010).

Catarina Frazão Santos ${ }^{1 \star}$, Tundi Agardy², Francisco Andrade', Manuel Barange ${ }^{3,4}$, Larry B. Crowder ${ }^{5,6}$, Charles N. Ehler ${ }^{7,8}$, Michael K. Orbach ${ }^{5,9}$ and Rui Rosa ${ }^{1}$
${ }^{1}$ MARE - Marine and Environmental Sciences Centre, Laboratório Marítimo da Guia, Faculdade de Ciências, Universidade de Lisboa, Avenida Nossa Senhora do Cabo, 2750-374 Cascais, Portugal. 2Sound Seas, 6620 Broad Street, Bethesda, Maryland 20816, USA. ${ }^{3}$ Fisheries and Aquaculture Department, Food and Agriculture Organization, Viale delle Terme di Caracalla, 00153 Roma, Italy. ${ }^{4}$ Plymouth Marine Laboratory, Prospect Place, Plymouth PL13DH, UK. ${ }^{5}$ Center for Ocean Solutions, Stanford University, 99 Pacific Street, Suite 555E, Monterey, California 93940, USA. ${ }^{6}$ Hopkins Marine Station, Stanford University, 120 Oceanview Boulevard, Pacific Grove, California 93950, USA. ${ }^{7}$ Ocean Visions Consulting, 213B Boulevard Saint-Germain, 75007 Paris, France. ${ }^{8}$ Intergovernmental Oceanographic Commission, UNESCO, 7 Place de Fontenoy, 75007 Paris, France. ${ }^{9}$ Duke University Marine Laboratory, Nicholas School of the Environment and Earth Sciences, Duke University, 135 Duke Marine Lab Road, Beaufort, North Carolina 28516, USA.

*e-mail: cfsantos@fc.ul.pt

Additional information

Supplementary information is available in the online version of this paper. 